\title{
The role of anti-Müllerian Hormone (AMH) in girls and adolescents
}

\author{
Iwona J. Czech(1, Agnieszka Drosdzol-Cop(1) \\ Chair and Department of Gynecology, Obstetrics and Oncological Gynecology, School of Health Science in Katowice, \\ Medical University of Silesia, Poland
}

\begin{abstract}
Anti-mullerian hormone (AMH) is produced by the granular cells of primary, preantral and antral follicles. The circulating levels of AMH in adult women reflect the number of remaining primordial follicles. AMH determination plays an increasingly important role in diagnostics in endocrinology and gynecology in adult women. Although the determination of AMH levels is used in pediatric practice, still little is known about its role in various pubertal disorders in girls. This article presents the clinical use of AMH in girls and adolescents.
\end{abstract}

Key words: Anti-Müllerian Hormone; AMH; adolescents; puberty

Ginekologia Polska 2021; 92, 7: 525-527

\section{INTRODUCTION}

Anti-Müllerian Hormone (AMH), also known as the factor that inhibits the development of the Müllerian ducts, is a dimeric glycoprotein that belongs to the family of transforming growth factors $\beta$ (TGF $\beta$ family) $[1,2]$, which has been predominantly known for its role in male sexual differentiation. The gene encoding AMH in humans is located on chromosome 19 p13.3 and it contains five exons. The gene for the AMH receptor type 2 is located on chromosome 12p13. The biological action of AMH depends on binding to the specific AMH type II receptor (AMH-RII), which expression has been demonstrated in the mesenchymal cells surrounding the Müller ducts, in testes (Sertoli and Leydig cells), and in granular and TEIC cells of the ovary. The receptor is a single transmembrane protein with serine- threonine kinase activity [2]. AMH expression and secretion are inhibited by androgens and estrogens, and in the situation of their deficiency or receptor defect also by gonadotrophins [1, 2].

Until about the fifth week of pregnancy (in the non-sexually differentiated phase), both sexes have buds of both male and female genital structures, Wolff tubes and Müller tubes. In Y chromosome fetuses carrying the SRY gene, around seven weeks of gestation, testes begin to develop, and then Sertoli cells begin to secrete $\mathrm{AMH}$, which causes the Müllerian ducts to overgrow. Leydig cells begin to produce testosterone, which is responsible for transforming the
Wolff's ducts into epididymis, seminal vesicles, ejaculatory ducts, and the abdominal part of the prostate. The external male genitalia develop under the influence of dihydrotestosterone (DHT) $[3,4]$. The maximum production of this hormone is observed between 12 and 16 weeks of gestation, which persists at a high level until reaching sexual maturity, then it significantly decreases in adult men [2]. In female fetuses, the lack of the SRY gene and the lack of AMH secretion determine the differentiation of the Müllerian ducts, the atrophy of the Wolff ducts and the development of the female genital organs in the fetus. The Müllerian ducts properly develop into the fallopian tubes, uterus, cervix and the upper part of the vagina $[3,5]$. In female fetuses, the production of $\mathrm{AMH}$ does not start until around 36 weeks of gestation, which is much later than the period of Mullerian duct sensitivity to $\mathrm{AMH}$.

AMH is produced by the granular cells of primary, preantral, and early antral follicles. The highest concentration of AMH is shown by small antral follicles (2-4 $\mathrm{mm}$ in diameter). Even though the concentration of $\mathrm{AMH}$ in the blood is much lower than the concentration in the follicle, it correlates very well with it, which relates to usefulness in practice [6].

\section{The role of $\mathrm{AMH}$ in adult women}

$\mathrm{AMH}$ determination can be performed regardless of the phase of the menstrual cycle and the use of hormonal

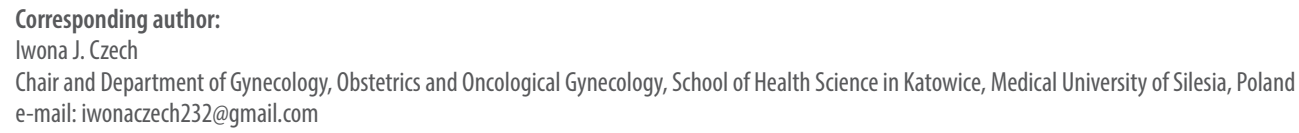


contraception. AMH determination plays an increasingly important role in diagnostics in endocrinology and gynecology in adult women [2, 4, 7-10]. With age, the number of ovarian follicles in a woman decreases, which translates into a decrease in $\mathrm{AMH}$ concentration in the blood (up to undetectable values after menopause), so the level of $A M H$ reflects the aging process of the ovary [4]. Therefore, AMH is considered one of the best indicators of ovarian reserve, and therefore it is also considered a marker of the assessment of a woman's reproductive potential $[7,9]$. Reduced AMH concentrations are observed not only in the physiological aging of the ovary, but also in the premature ovarian failure (POF) [11]. There are also reports on the usefulness of monitoring $\mathrm{AMH}$ levels in predicting the age at which a woman will reach menopause [11]. Currently, many studies on the concentration of $\mathrm{AMH}$ concern its role in polycystic ovary syndrome (PCOS). The concentration of AMH was 2-3 times higher in women suffering from PCOS than in women with ovaries with a normal number of follicles [10, 11]. Research shows that $A M H$ may also be a marker of hyperandrogenism in PCOS [10]. According to some reports, the concentration of AMH may also be useful in predicting the return of ovulatory cycles in obese women with PCOS after weight loss [2]. Although there is currently no clearly defined upper cut-off point of the AMH level, it is postulated to include this test in PCOS diagnostics.

Moreover, AMH may be a useful marker of granulosa-cell tumors (folliculoma) and their recurrence. In these clinical situations, AMH levels can be very high and correlate with tumor size [11].

\section{The role of $\mathrm{AMH}$ in girls}

After birth, in female infants, blood levels of AMH are very low (lower than in male fetuses), even undetectable. Research on the changes in AMH levels in the early stages of puberty is quite limited and reports remain inconsistent. A few studies AMH levels rise during infancy and they are stable from childhood Hagen et al. conducted a study in which they tried to determine the individual concentration of AMH in each of the examined girls. They found that circulating $\mathrm{AMH}$ shows only slight fluctuations during childhood and adolescence, and a random measurement of $\mathrm{AMH}$ appears to be representative. The negative AMH-FSH correlation in pre-pubertal girls supported the statement that $\mathrm{AMH}$ is a quantitative marker of ovarian follicles even in young girls. The mean AMH levels ranged between 5 and $54 \mathrm{pmol} / \mathrm{L}$. 10 girls had a mean AMH level below the cut-off of $8 \mathrm{pmol} / \mathrm{L}$, of which four had not yet entered puberty. However, the relationship between the AMH level and the period since menarche has not been assessed [12, 13]. A later study by Hagen et al. shows that three years before the onset of puberty, $\mathrm{AMH}$ increases, while within two years after the beginning of puberty, AMH decreases by $30 \%$ [14].

The increased concentration of circulating $\mathrm{AMH}$ in the pre-pubertal period allowed for the recognition of the hormone as a marker of ovarian follicle growth because its growth occurs in the period when the hypothalamic-pituitary-ovary axis is still inactive [15]. Some statistical models suggest that the highest rate of recruitment of nongrowing follicles takes place between birth and 14 years of age which is an age of menarche in most girls [16].

\section{Precocious puberty}

The concentration of AMH may be a marker of the onset as well as the progression of sexual maturation in girls. Chen et al., in their study which comprised 83 girls with diagnosed central precocious puberty (CPP), found out that $\mathrm{AMH}$ and inhibin levels are potential biomarkers for distinguishing various progression rates in girls with $\mathrm{CPP}$ and they can assist in the distinction of progressive CPP and slowly progressive CPP at the time of diagnosis [17]. Also, Lashen et al. support the thesis that the rise of $\mathrm{AMH}$ and inhibin $\mathrm{B}$ levels in prepubertal childhood may suggest the onset of central puberty [16]. Xue et al., in their study about AMH use in precocious puberty progression conclude, that although $\mathrm{AMH}$ may not be a good indicator for early diagnosis, it has significance in the auxiliary diagnosis, differential diagnosis, treatment and prognosis of sexual puberty disorders in children [18].

\section{PCOS}

AMH levels in adolescents have been also proved to have a clinical impact in young patients with PCOS. Kim et al. states that AMH may be a useful biomarker for the diagnosis of PCOS in obese girls, as AMH concentrations are twice higher in obese PCOS girls and correlate with hyperandrogenemia with the cut-ff point of $6.26 \mathrm{ng} / \mathrm{mL}$ [19]. Efthymiadou et al. proved that girls with premature adrenarche, especially those from mother with a history of PCOS, could have a higher risk of developing PCOS later in life, because they have increased serum AMH [20].

\section{Premature ovarian insufficiency}

Low or even undetectable level of $\mathrm{AMH}$ is a good marker of premature ovarian insufficiency (POI) in girls. At young age, POI occurs mostly in girls with Turner Syndrome and in girls receiving gonadotoxic treatment [21].

\section{Granulosa cell tumors}

Although only a few percent of folliculomas are seen in girls in adolescents, we cannot forget about this pathology. Granulosa cell tumors may present as precocious puberty. High (masculine) levels of AMH in girls should be considered 
a manifestation of ovarian pathology, however, we should not exclude ovarian tumor in girl with $\mathrm{AMH}$ levels within the reference range [21]. As mentioned previously, $\mathrm{AMH}$ may be an indicator of tumor recurrence.

\section{Determination of the presence of testicular tissue}

AMH concentrations within the male reference range are highly indicative of testicular tissue. Low or undetectable levels of $\mathrm{AMH}$ indicate either anorchia or dysgenetic testicular tissue or presence of ovarian tissue. This clinical implication is used when a child is born with bilaterally absent testes or ambiguous genitalia [21].

\section{Other pathologies}

Codner et al. conducted the study, which showed that AMH levels are increased in girls with type 1 diabetes (T1D) during childhood and decrease during puberty, which suggests, that T1D modulates ovarian follicle growth differently once gonadotrophin levels rise. What is more, Codner et al. suggest, that girls with T1D exhibit similar endocrine findings to other groups at increased risk of developing PCOS [13].

Even though the literature provides information on the use of $\mathrm{AMH}$ in the diagnosis of many of the above-mentioned pathologies, the reference values of $\mathrm{AMH}$ concentration in prepubertal and postmenarcheal girls are still poorly detailed. The knowledge of AMH norms in girls would enable further research on various types of pathologies occurring in them. AMH could become much more useful in the diagnosis of premature puberty, delayed puberty, thelarche praecox, menarche praecox, and the diagnosis of ovarian tumors in girls.

\section{Conflict of interest}

The authors declare no conflict of interest

\section{REFERENCES}

1. Rajpert-De Meyts E, Jørgensen N, Graem N, et al. Expression of anti-Müllerian hormone during normal and pathological gonadal development: association with differentiation of Sertoli and granulosa cells. J Clin Endocrinol Metab. 1999; 84(10): 3836-3844, doi: 10.1210/jcem.84.10.6047, indexed in Pubmed: 10523039.

2. WikarekT, Olszanecka-Glinianowicz M, Chudek J, et al. Hormon anty-Müllerowski a zaburzenia płodności u otyłych kobiet i kobiet z zespołem policystycznych jajników. Ginekol Pol. 2011; 82(3): 205-209.

3. Bręborowicz G. Położnictwo i ginekologia. PZWL, Warszawa 2015.

4. Krawczyńska M, Słowińska-Srzednicka J. Zastosowanie oznaczeń stężeń hormonu antymüllerowskiego (AMH) w diagnostyce chorób endokrynnych. Borgis - Postępy Nauk Medycznych. 2016; 12: 921-928.

5. Behringer RR, Finegold MJ, Cate RL. Müllerian-inhibiting substance function during mammalian sexual development. Cell. 1994; 79(3): 415-425, doi: 10.1016/0092-8674(94)90251-8, indexed in Pubmed: 7954809.

6. Lukaszuk K, Ludwikowska B, Liss J, et al. Decreasing quality of the new generations of anti-Müllerian hormone assays. Biomed Res Int. 2014; 2014: 165352, doi: 10.1155/2014/165352, indexed in Pubmed: 24738048.

7. Dewailly D, Andersen CY, Balen A, et al. The physiology and clinical utility of anti-Mullerian hormone in women. Hum Reprod Update. 2014; 20(3): 370-385, doi: 10.1093/humupd/dmt062, indexed in Pubmed: 24430863.

8. Garg D, Tal R. The role of AMH in the pathophysiology of polycystic ovarian syndrome. Reprod Biomed Online. 2016; 33(1): 15-28, doi: 10.1016/j. rbmo.2016.04.007, indexed in Pubmed: 27174394.

9. Kruszyńska A, Słowińska-Srzednicka J. Anti-Müllerian hormone (AMH) as a good predictor of time of menopause. Prz Menopauzalny. 2017; 16(2): 47-50, doi: 10.5114/pm.2017.68591, indexed in Pubmed: 28721129.

10. Dewailly $D$, Pigny $P$, Soudan $B$, et al. Reconciling the definitions of polycystic ovary syndrome: the ovarian follicle number and serum anti-Müllerian hormone concentrations aggregate with the markers of hyperandrogenism. J Clin Endocrinol Metab. 2010; 95(9): 4399-4405, doi: 10.1210/jc.2010-0334, indexed in Pubmed: 20610596.

11. Dębski R, Kruszyńska A. Diagnostyka endokrynologiczna w ginekologii. In: Zgliczyński W, Kruszyńska A. ed. Wielka interna - endokrynologia, wyd. Il. Medical Tribune Polska, Warszawa 2020.

12. Hagen $C P$, Aksglaede L, Sørensen $K$, et al. Serum levels of anti-Müllerian hormone as a marker of ovarian function in 926 healthy females from birth to adulthood and in 172 Turner syndrome patients. J Clin Endocrinol Metab. 2010; 95(11): 5003-5010, doi: 10.1210/jc.2010-0930, indexed in Pubmed: 20719830.

13. Codner $E$, Iñiguez $G$, Hernández IM, et al. Elevated anti-Müllerian hormone $(\mathrm{AMH})$ and inhibin $\mathrm{B}$ levels in prepubertal girls with type 1 diabetes mellitus. Clin Endocrinol (Oxf). 2011; 74(1): 73-78, doi: 10.1111/j.13652265.2010.03887.x, indexed in Pubmed: 21039723.

14. Hagen $C P$, Aksglaede $L$, Sørensen $K$, et al. Individual serum levels of anti-Müllerian hormone in healthy girls persist through childhood and adolescence: a longitudinal cohort study. Hum Reprod. 2012; 27(3): 861-866, doi: 10.1093/humrep/der435, indexed in Pubmed: 22215627.

15. de Vet $A$, Laven JSE, de Jong FH, et al. Antimüllerian hormone serum levels: a putative marker for ovarian aging. Fertil Steril. 2002; 77(2): 357-362, doi: 10.1016/s0015-0282(01)02993-4, indexed in Pubmed: 11821097.

16. Lashen $H$, Dunger DB, Ness $A$, et al. Peripubertal changes in circulating antimüllerian hormone levels in girls. Fertil Steril. 2013; 99(7): 2071-2075, doi: 10.1016/j.fertnstert.2013.01.139, indexed in Pubmed: 23419927.

17. Chen $T, W u H, X i e ~ R$, et al. Serum Anti-Müllerian Hormone and Inhibin $B$ as Potential Markers for Progressive Central Precocious Puberty in Girls. J Pediatr Adolesc Gynecol. 2017; 30(3): 362-366, doi: 10.1016/j. jpag.2017.01.010, indexed in Pubmed: 28161677.

18. Xue J, Song W, Si M, et al. Serum Kisspeptin and AMH Levels Are Good References for Precocious Puberty Progression. Int J Endocrinol. 2020; 2020: 3126309, doi: 10.1155/2020/3126309, indexed in Pubmed: 33293954.

19. Kim JY, Tfayli H, Michaliszyn SF, et al. Anti-Müllerian hormone in obese adolescent girls with polycystic ovary syndrome. J Adolesc Health. 2017; 60(3): 333-339, doi: 10.1016/j.jadohealth.2016.10.015, indexed in Pubmed: 27998701

20. Efthymiadou A, Bogiatzidou M, Kritikou D, et al. Anti-Müllerian hormone in girls with premature adrenarche: the impact of polycystic ovary syndrome history in their mothers. J Pediatr. 2019; 205: 190-194, doi: 10.1016/j.jpeds.2018.09.064, indexed in Pubmed: 30529136.

21. Lindhardt Johansen $M$, Hagen $C P$, Johannsen $T H$, et al. Anti-müllerian hormone and its clinical use in pediatrics with special emphasis on disorders of sex development. Int J Endocrinol. 2013; 2013: 198698, doi: 10.1155/2013/198698, indexed in Pubmed: 24367377. 